\title{
OUANTIFICAÇÃO E PRECIFICAÇÃO DE RISCO DE CRÉDITO ATRAVÉS DO MODELO DE OPÇÕES
}

Luiz Carlos Jacob Perera Doutorando em Administração pela EAESP/ FGV; professor e coordenador do Curso Especial de Administração da Universidade Mackenzie; consultor financeiro. E-mail: jperera @br.homeshopping.com.br

RESUMO: O trabalho está dividido em duas partes. Na primeira, são desenvolvidos os conceitos fundamentais para o entendimento do modelo de Black e Scholes com exemplos de sua utilização. Na segunda, inicialmente discutese o conceito de risco das empresas. A seguir, através de uma aplicação, demonstra-se como uma empresa pode alterar favoravelmente o equilíbrio de risco e retorno: aceitando mais risco, aumentando seu débito ou pagando dividendos extras para os acionistas. Finalmente, mostra-se como os credores podem defender-se dessas manobras alterando adequadamente a taxa de juros, de forma a compensar o maior risco assumido e, assim, manter a posição de equilíbrio inicial entre risco e retorno.

ABSTRACT: This work is divided in two parts. In the first part, are developed the fundamental concepts to understand the Black-Scholes Model and its use is showed through an example. In the second part, it is initially discussed the concept of firm risk. In sequence, is proved how the company can favorably change the risk-return equilibrium: accepting more risk, increasing its debt or paying additional dividends to the stockholders. Finally, it is showed how the debtholders can protect themselves from this decisions, adequately changing the interest rates to compensate the increase in risk, maintaining the initial condition of the risk-return equilibrium.

PALAVRAS-CHAVE: Modelo de Precificação de Opções (OPM), quantificação, precificação, risco, crédito. KEY WORDS: Option Pricing Model (OPM), quantifying, pricing, risk, credit. 


\section{CONCEITOS BÁSICOS SOBRE OPÇÕES E SUA UTILIZAÇÃO}

\section{Introdução}

A oportunidade deste artigo decorre das medidas governamentais que aparentemente trouxeram as taxas de inflação para valores administráveis, indicando uma razoável estabilidade financeira. Devemos ressaltar que, em especial os bancos, a partir da queda da inflação tiveram esgotada uma de suas mais importantes e seguras fontes de resultados, os floats, decorrentes do grande volume de aplicações financeiras de seus clientes, geralmente investidos em seguros títulos governamentais. Com o esvaziamento dessa valiosa fonte de recursos, os bancos foram forçados a retomar seu objetivo, ou seja, o de intermediar empréstimos através do crédito.

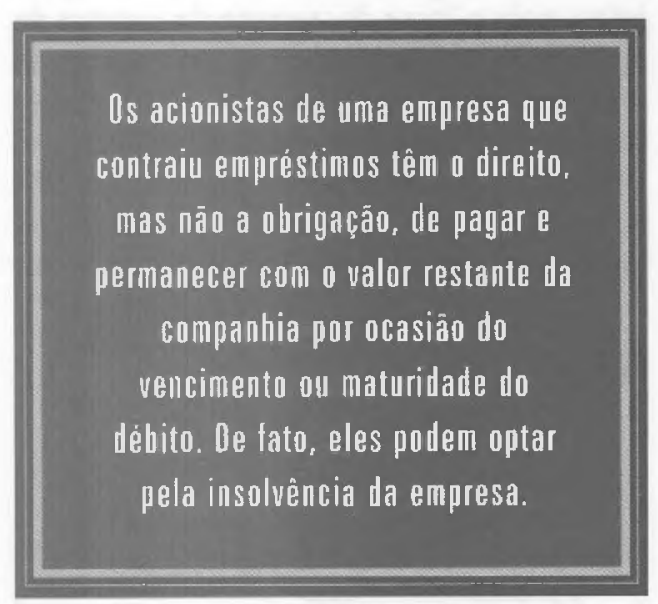

Os resultados decorrentes de empréstimos advêm da administração do risco da operação, sobre a qual deve ser cobrada uma taxa justa (adequada ao risco) e sob pena do intermediário financeiro ou perder boas oportunidades de ganho - por cobrar taxas excessivas - ou expor-se além da taxa cobrada, fato que também pode lhe trazer desagradáveis prejuízos.

As atividades financeiras normalmente são desenvolvidas através da modelagem de princípios teóricos. A vantagem de utilizar um modelo é a redução do tempo e do custo necessários para avaliar uma alternativa. Isto pode levar o indivíduo a desenvolver a geração de novas alternativas ou a mudan- ças na formulação dos problemas.'

Um dos modelos mais conhecidos e utilizados no mercado financeiro é o Modelo de Precificação de Opções (OPM), desenvolvido em 1973 por Black e Scholes ${ }^{2}$ e que tem se mostrado extremamente versátil e eficaz em sua concepção pois, além de precificar ativos específicos negociados em bolsa, tem sido aplicado com sucesso na precificação de outros ativos do mercado, inclusive na atividade creditícia.

Vejamos como diversos autores conceituam opções e tratam suas aplicações:

- Segundo Ross ${ }^{3}$, uma opção é um contrato que dá a seu titular o direito de comprar ou vender um ativo a um preço determinado numa data certa ou antes dela. As opções são um tipo especial de contrato financeiro porque dão ao seu comprador o direito, mas não a obrigação de fazer alguma coisa. O comprador utiliza a opção apenas se for de seu interesse; alternativamente, a opção poderá ser jogada fora.

- Estendendo o conceito de opção, Weston e Copeland ${ }^{4}$ afirmam que há uma quantidade surpreendente de contratos que correspondem a essa descrição. Por exemplo, os acionistas de uma empresa que contraiu empréstimos têm o direito, mas não a obrigação, de pagar e permanecer com o valor restante da companhia por ocasião do vencimento ou maturidade do débito. De fato, eles podem optar pela insolvência da empresa.

$\Rightarrow$ Black e Scholes 5 , autores do modelo mais utilizado para precificaçāo de opções, observaram que os princípios aplicados aos preços das opções podem ser usados para avaliar outros ativos complexos na forma de exigibilidades contingenciais, tal como o patrimônio líquido de uma firma alavancada. Deste ponto de vista, os acionistas de uma empresa possuem uma opção de compra que lhes dá o direito de comprar a firma de volta dos credores pagandolhes o valor facial do empréstimo na maturidade. Um grande número de aplicações utilizando o OPM foram desenvolvidas a partir de então.

Outras aplicações do modelo de opções foram também relatadas por $\mathrm{Smith}^{6} \mathrm{em}$ seu abrangente artigo, no qual faz uma revisão de autores e aplicações do OPM.
1. HOLLOWAY, C. Decision making under uncertainty models and choices. New Jersey: Prentice-Hall, p. 21, 1979

2. BLACK, F, \& SCHOLES M. The pricing of options and corporate liabilities. Journal of Polifical Economy, 81 (MayJune), p. $637-654,1973$.

3. ROSS, S. A. WESTERFIELD, R. D. \& JEFFREY, F. J. Administracão financeira. São Paulo: Atlas. 1995.

4. WESTON, J.F. \& COPELAND, T. E Manageriai finance. Texas: Driden. $\mathrm{o}$. $435,1992$.

5. Idem, ibidem, p. 436 .

6. SMITH, C. Jr. Option pricing: a review. Joumal of Financial Economics (Jan-Mar). p. $1-51,1976$. 
Segundo ele, "o modelo é também aplicado por Merton (1974) para analisar os efeitos do risco sobre o valor dos débitos corporativos; por Galay e Masulis para examinar os efeitos de fusões, aquisições, expansões de escala, e desinvestimentos sobre os valores relativos dos débitos $e$ patrimônio líquido das empresas; por Ingersoll para avaliar as cotas dos dual purpose funds; por Black para avaliar opções sobre commodities, contratos a termo e contratos futuros."

Pelas afirmações dos autores citados, verifica-se a grande importância e generalidade do OPM, que no entanto continua obscurecido por outros approachs, como o Capital Asset Pricing Model (CAPM) de Sharpe ${ }^{7}$, no que diz respeito a sua utilização pelos profissionais de mercado.

Neste texto pretendemos, com a utilização do OPM, dar uma contribuição para o tema que se tornou especialmente importante após o controle das elevadas taxas de inflação: a quantificação e precificação do risco de crédito administrado pelas instituições financeiras e não-financeiras.

\section{Considerações básicas sobre opções}

Opções apresentam-se de várias formas, mas todas mantêm algumas características básicas. O titular tem o direito - mas não a obrigação - de comprar (call) ou vender (put) um determinado ativo por um preço ajustado num dado prazo. Essa opção, para vender ou comprar, tem um valor que deve ser pago ao emitente da opção, o lançador, que é chamado prêmio. A opção é exercida por um preço previamente acertado, o preço de exercício (strike). Uma opção que se torna lucrativa, se exercida ao preço corrente do ativo é chamada no-dinheiro ou dentro-do-dinheiro (in-the-money). Inversamente, se não for lucrativa, é chamada fora-do-dinheiro (out-of-the-money).

Se a opção só pode ser exercida na data de vencimento é uma opção européia. Se pode ser exercida a qualquer momento antes da data de vencimento é uma opção americana. As opções de compra negociadas no Bovespa 7. SHARPE, W. F. Capital asset prices: a theory of market equilibrium under conditions of risk. Journal of Finance 19 (September), D. 425-42, 1964.
Vejamos, a seguir, o comportamento das opções de compra e de venda, do tipo européia

\section{Opção de compra}

A relação entre o prazo de vencimento, o preço de exercício e a rentabilidade de opção européia, sem correção, é mostrada na Figura 1. A figura 1(a) mostra a rentabilidade possível de uma opção de compra com um preço de exercício de $\$ 10$ e um prêmio de $\$ 2$. Até o preço da ação atingir $\$ 10$, a opção de compra não será exercida, resultando num prejuízo de $\$ 2$ correspondente ao valor pago pelo prêmio da opção. A partir do valor de $\$ 10$ a opção será valorizada para cada centavo de valorização da ação; daí o ângulo de 45 graus. Até $\$ 12$ o valor do prêmio estará sendo coberto, reduzindo o prejuízo do tomador da opção. Exatamente quando a ação atingir $\$ 12$, o tomador da opção estará sem lucro nem prejuízo, pois o lucro decorrente da compra da ação, pelo exercício da opção, e a venda da mesma ao preço de mercado cobrirá a despesa com o pagamento prévio do prêmio. A partir de $\$ 12$, para cada centavo de valorização da ação, o titular ou tomador da opção estará tendo lucro pelo mesmo valor.

\section{Figura 1}

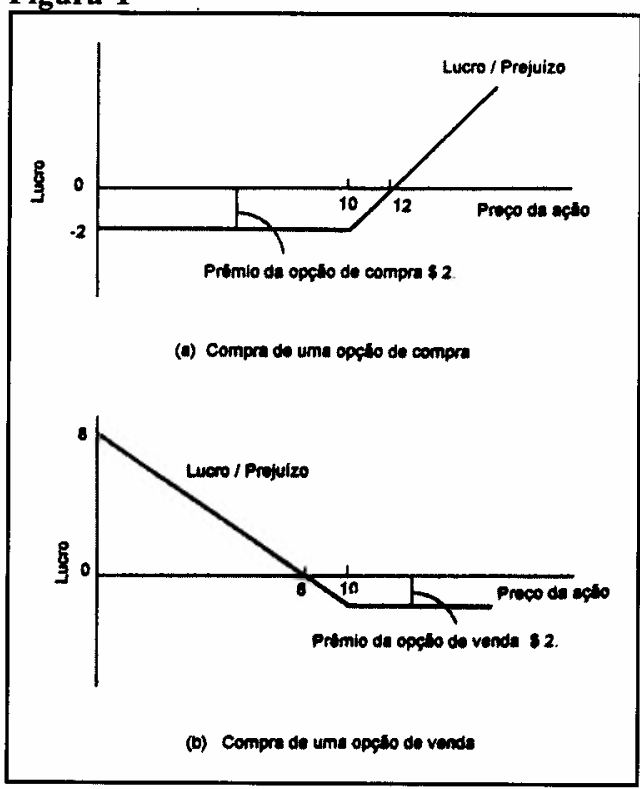

De uma forma geral, o valor de uma opção de compra $C$, na data de vencimento, 
com o preço da ação $S$, naquela data, e preço de exercício $X$ é

$$
C=\operatorname{MAX}(0, S-X)
$$

onde $M A X$ refere-se ao valor máximo de $(S-X)$ ou 0 . Em outras palavras, o valor da opção de compra será a diferença entre o preço da ação e o preço de exercício ou zero, dependendo qual deles for o maior. O lucro do titular da opçāo é $(C-a)$, sendo $a$ o valor pago pelo prêmio da opção, na data em que adquiriu o direito de compra (call). Vale a pena lembrar que um contrato de uma opção de compra é um jogo de média zero, isto é, a rentabilidade do lançador é o negativo da rentabilidade do tomador.

\section{Opção de venda}

A Figura 1 (b) mostra a rentabilidade ao comprar uma opção de venda com um preço de exercício de $\$ 10$ e prêmio de \$2. Quando o preço do ativo sobe acima de $\$ 8$ o lucro do tomador acaba, pois o prêmio pago pela opção fica sem cobertura. Progressivamente, para cada centavo de alta da ação a partir de $\$ 8$, a opção de venda cairá em igual valor (ângulo de 45 graus). Por exemplo, se o preço da ação sobe de $\$ 6$ para $\$ 7$, o valor da opção cairá de $\$ 4$ para $\$ 3$. Com a ação sendo negociada a $\$ 10$, o valor da opção de venda será zero e o tomador terá como prejuízo o preço pago pelo prêmio.

De uma formá geral, o preço de uma opção de venda $P$, na data de vencimento, com o preço da ação $S$, naquela data, e o preço de exercício $X$ é:

$P=\operatorname{MAX}(0, X-S)$

Se o prêmio da opção era $b$, na data em que foi adquirido o direito de venda ( $p u t)$, então o lucro do titular da opção de venda é ( $P$ - b). O lucro do lançador da opção de venda será o valor negativo da rentabilidade do tomador da opção.

\section{Usando arbitragem para avaliar uma opção}

O problema crucial de uma opçāo é a definição de seu valor. Este problema foi solucionado de forma magistral por BlackScholes; ; no entanto, devido à complexida- de do modelo, que dificulta sua demonstração, vamos seguir um exemplo desenvolvido por Shapiro ${ }^{9}$ para mostrar como funciona a técnica de Black-Scholes na avaliação de uma opção de compra.

Suponha que o preço corrente da Santana Hills Co. é de $\$ 100$ por ação e também o preço de exercício de uma opção de compra, com vencimento para um ano. Para tornar as coisas mais simples, vamos supor que, ao final de um ano, o preço da Santana Hills possa subir para $\$ 110$ ou cair para $\$ 90$. Considerando uma taxa de juros de $5 \%$ ao ano, podemos mostrar que o preço da opção deve ser avaliado em $\$ 7,143$.

Se o preço da ação, no seu vencimento, subir para \$110, a opção estará no-dinheiro e valerá $\$ 10$. Por outro lado, se no final do ano a ação estiver valendo $\$ 90$, a opção expira sem valor, ou, no jargão de mercado, "vira pó". Os possíveis resultados para essa opção são:

\begin{tabular}{|lrr|}
\hline Preço da Açāo = & $\$ 90$ & $\$ 110$ \\
\hline Valor da Opção de Compra & 0 & 10 \\
\hline
\end{tabular}

Os resultados dessa opção podem ser exatamente duplicados comprando-se uma ação da Santana Hills financiada em parte por \$ 85,714 com o dinheiro tomado emprestado. ${ }^{10}$ Esse portfólio tem valor corrente líquido de $\$ 14,286$ igual ao preço da ação menos os \$ 85,714 do dinheiro emprestado. Os resultados desse portfólio, ao final de um ano, pagando-se o empréstimo com os juros devidos são os seguintes:

\begin{tabular}{|l|rc|}
\hline Preço da Ação $=$ & $\$ 90$ & $\$ 110$ \\
\hline Valor de uma ação & 90 & 110 \\
\hline $\begin{array}{l}\text { Pagamento do empréstimo } \\
\text { mais juros de 5\% }\end{array}$ & 90 & 90 \\
\hline Resultado Total & $\$ 0$ & $\$ 20$ \\
\hline
\end{tabular}

Devido ao fato de os resultados desse portfólio replicarem exatamente os resultados de quem possui duas opções de compra, seus valores devem ser idênticos, além disso, considerando o resultado líquido do portfólio igual a $\$ 14,286$, uma opção de compra deve valer exatamente a metade desse valor, ou $\$ 7,143$.

Se o preço da opção de compra diferisse
8. BLACK, F. \& SCHOLES, M. Op. cit

9. SHAPIRO, A. C. Modern corporate fnance. New York: Macmillan. p. 150 1990.

10. Para construir uma posição ałavancada sobre 0 ativo básico, isto $e^{\prime}$ a ação que ô̂ exatamente o mesmo resultado que a opçāo de compra, necessário tomar emprestado um montante Igual a $\left(S_{i}-C_{L}\right) /(t+r)$ onde $S$, é o valor mais baixo esperado para a açẫo $S$, ào cabo de um ano; $C_{1}$ é o valor da opção de compra $C$ quanda 0 valor do ativo básico no vencimento é $S$, i a $r$ é a taxa de juros do empréstimo. Substituindo pelos números do texta temos o montante a ser tomado emprestado igual a $(90-0) /(1,05)=$ $\$ 85,714$. 
11. BLACK, F. \& SCHOLES, M. Op. cit.

12. SANVICENTE, A. Z. Avaliaçāo de opçöes de compra de açóes em condiģóes de incerteza sobre a taxa de juros de mercado aberto. São Paulo: Universidade de São Paulo, p. 32, 1983 (Tese de livredocência). desse valor haveria possibilidades de arbitragem, isto é, poderiam ser auferidos lucros sem risco. Mas tal situação não permaneceria por muito tempo. No processo de capitalizar seus lucros os investidores, ao perpetrarem a arbitragem, conduziriam os preços da opção de compra ao seu valor de equilíbrio de $\$ 7,143$.

\section{A rigueza ganha polos proprietários}

da empresa corresponde a valor

perdido pelos credores. Este é o

risco para 0 qual credores e

investidores

devem estar atentos

\section{O modelo Black-Scholes}

A hipótese considerada anteriormente, a de que somente dois movimentos podem ocorrer com os preços das ações no prazo de um ano, parece bastante irrealista. Mas se trocarmos a palavra ano por período e dividirmos os períodos por um número bastante grande, aproximaremos os intervalos de zero; nessa situação, a hipótese de ocorrerem apenas dois movimentos com os preços das ações no próximo microssegundo, suavemente para cima ou suavemente para baixo parece ser bastante realista. De fato, o grau de alavancagem - quantidade de dinheiro tomado emprestado - deve ser atualizado continuamente, assim como o preço do ativo básico, e o prazo para a maturidade da opção.

A tarefa bastante difícil de obter um modelo que satisfizesse às condições propostas foi conseguida, em 1973, por Black-Scholes. ${ }^{11}$ Sanvicente, ${ }^{12}$ em sua tese de livre-docência, apresenta os principais trabalhos que precederam o modelo Black-Scholes, assim como a derivação do modelo original.

Vejamos inicialmente as hipóteses que

dos os indivíduos;

- não há restrições para vendas a descoberto;

- o processo estocástico dos ativos é estacionário;

- a taxa livre-de-risco é constante ao longo do tempo;

- o ativo básico não paga dividendos ou outros desembolsos de caixa de qualquer espécie;

- o preço da ação tem distribuição "lognormal".

A maioria dessas hipóteses pode ser relaxada, sem alterar significativamente o Modelo de Precificação de Opções.

A fórmula de Black-Scholes, que resulta na avaliação de uma opção de compra Européia, antes de seu vencimento é a seguinte:

$\begin{aligned} C & =S N\left(d_{1}\right)-X e^{-r T} N\left(d_{2}\right) \\ \text { sendo } d_{1} & =\frac{\ln (s / x)+\left(r+0,5 \sigma^{2}\right) T}{\sigma \sqrt{T}} \\ d_{2} & =d_{1}-\sigma \sqrt{T}\end{aligned}$

Os termos $N\left(d_{1}\right)$ e $N\left(d_{2}\right)$ são as probabilidades acumuladas para uma variável normal $\mathrm{Z}$, lembrando que uma variável normal padronizada tem média zero e desvio padrão um.Uma rápida inspeção da fórmula de Black-Scholes mostra que o valor de uma opção de compra é uma função do preço do ativo-objeto $S$, o preço de exercício $X$, o prazo para a maturidade $T$, a variância instantânea, e a taxa livre-de-risco $r$.

\section{Fatores que determinam o valor das opções}

Alguns fatores determinam o valor de uma opção de compra (call) e podem ser divididos em dois conjuntos. $O$ primeiro diz respeito às características básicas do contrato, que são o preço de exercício e a data de vencimento. $\mathrm{O}$ segundo conjunto de fatores que afetam o preço da opção dizem respeito às características do ativo-objeto e do mercado.

Preço do ativo-objeto: quanto mais alto dão suporte ao modelo de precificação de opções, menos restritivas que as do CAPM:

- o mercado não tem friçcões, tais como custos de transações e impostos;

- as informações estão instantaneamente disponíveis e sem custo para too valor do ativo-objeto, os outros fatores permanecendo constantes, mais valiosa será a opção de compra. Isto ocorre em função da elevação dos valores absolutos decorrentes da variabilidade do ativo-objeto.

Preço de exercício: mantidas as outras va- 
riáveis constantes, quanto mais alto o preço de exercício de uma opção de compra, menor o seu valor, representando uma relação inversa. O valor de uma opção de compra não pode ser negativo, por maior que seja seu preço de exercício. Além disso, desde que haja alguma possibilidade de que o preço do ativo-objeto supere o preço de exercício antes da data de vencimento, a opção terá algum valor.

Data de vencimento: considerando duas opções idênticas, apenas variando o prazo de vencimento, ambas têm os mesmos direitos, mas a de prazo maior tem o adicional de tempo, portanto, deve valer mais.

Taxa de juros: os preços das opções de compra, como o de qualquer outro ativo, também dependem do nível das taxas de juros. $\mathrm{O}$ preço de exercício somente é pago quando a opção é de fato exercida. Variando apenas as taxas de juros, ocorrem efeitos tanto no valor presente do preço de exercício, quanto nos valores de $\left(d_{1}\right)$ e $\left(d_{2}\right)$. No entanto, há uma preponderância no efeito que ocorre no valor presente do preço de exercício que consequientente declina aumentando as taxas de juros e o valor do preço da opção supondo-se, por esse motivo, uma correlação direta entre ambos.

Variabilidade do ativo-objeto: $\operatorname{Ross}^{13}$ considera este o "fator-chave" pois, quanto maior a variabilidade do ativo subjacente, mais vale a opção de compra. Há uma distinção fundamental entre possuir uma opção sobre um ativo-objeto e possuir o próprio ativo. Se os investidores forem aversos ao risco, um aumento na variabilidade do ativo reduzirá seu valor. Entretanto, o titular de uma opção de compra tem direitos a resultados vinculados ao lado positivo da distribuição de probabilidades; logo, um aumento da variabilidade do ativo-objeto também aumenta a probabilidade de ultrapassar o preço de exercício da opção de compra e, conseqüentemente, seu valor de mercado. Deve-se considerar também que um aumento no lado esquerdo da distribuição de probabilidades é irrelevante, dado que o limite de seu preço é zero.

A relação entre o valor de uma opção antes de expirar, o valor do ativo básico e a linha de paridade de 45 graus entre $S$ e $X$ é mostrada na figura $2 .{ }^{14}$ A distância entre o valor da opção $C$ e a linha de paridade é conhecida como prêmio sobre a paridade. A linha cheia representa o valor intrínseco da opção. Ela iguala o valor pelo qual a op-
Figura 2

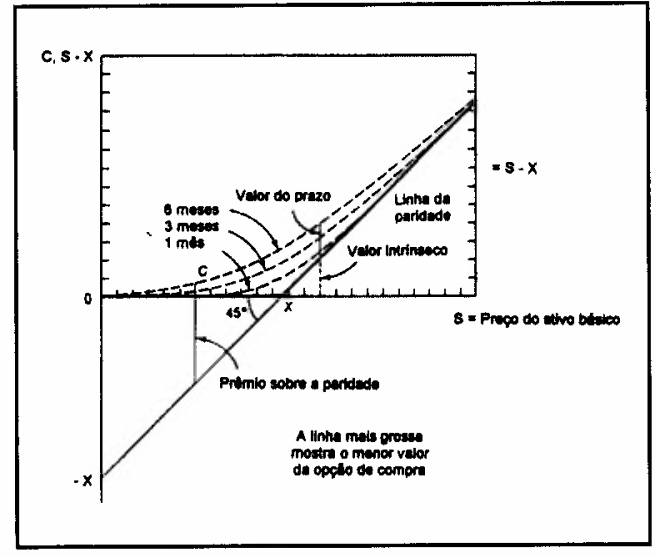

ção está no-dinheiro. Em outras palavras, ela representa o valor do exercício imediato da opção. Uma opção fora-do-dinheiro não tem valor intrínseco. Esta figura mostra que o valor intrínseco de uma opção para ativos com valores inferiores a $X$ é zero. Qualquer excesso sobre o valor intrínseco de uma opção é chamado de valor do prazo de um contrato.

Antes do vencimento, uma opção fora-dodinheiro tem somente valor do prazo, enquanto que uma opção no-dinheiro tem tanto valor intrínseco quanto valor do prazo. Este último reflete a probabilidade de seu valor intrínseco aumentar antes do vencimento. A probabilidade depende, entre outras coisas, da volatilidade do ativo básico. Como é mostrado na figura 2 , o valor do prazo de uma opção diminui quando a data de vencimento aproxima-se; uma opção com vida curta tem menos chances de aprofundar-se mais no dinheiro antes que expire. $\mathrm{Na}$ data de vencimento, o valor do prazo é zero e a opção vale somente o valor intrínseco.

A figura 2 também mostra que quando $S$ aproxima-se de zero, $C$ também faz o mesmo; à medida que $S$ torna-se infinitamente grande o valor da opção aproxima-se de ( $S$ - X). Em outras palavras, o valor do prazo de uma opção tende a zero deixando-a somente com seu valor intrínseco, quando aprofunda-se no-dinheiro ou fora-do-dinheiro. O mesmo acontece quando a opção aproxima-se da data de vencimento; complementarmente, o valor relativo ao prazo é maior quando o ativo está-no-dinheiro $(S=X)$.

Esses resultados permitem as seguintes conclusões: o preço zero de um ativo significa que não há qualquer chance desse ativo valer qualquer coisa no futuro. Se isso ocorrer, a opção irá expirar sem ser exercida e sem apre-
13. ROSS, S. A., WESTERFIELD, R. D. \& JEFFREY, F. J. Op. cit, p. 446.

14. SHAPIRO, A. C. Op. cit., p. 153 
15. A opção de compra com preço de exercicio de \$ 190,00 foi utilizada para encontrar o desvio-padrão instantâneo por ser a opçāo que teve o malor número de negociações $\{30.650\}$ naquela data. sentar qualquer valor, pois marca um valor presente de zero. Alternativamente, se o preço do ativo aumenta, a chance de que ele fique abaixo do preço de exercício diminui, aumentando a probabilidade da opção ser exercida eventualmente com um lucro de ( $S$ $X$ ). Se $S$ aumenta bastante, o exercício é praticamente assegurado e o valor da opção chegará a $(S-X)$. Em ambos os extremos $(S=0$ e $S=+a)$ o valor do prazo iguala-se a zero porque não há chance, que eventos futuros alterem a posição de exercício da opção. De outra forma, o preço da opção sempre excederá o valor de $(S-X)$, caso a opção for exercida hoje.

O fato de uma opção ter um valor de prazo positivo antes de seu vencimento resulta numa importante regra de decisão: uma opção sobre um ativo que não pague dividendos não deve nunca ser exercida antes do vencimento. $\mathrm{O}$ exercício rende ao titular $(S-X)$, mas em qualquer prazo, antes do vencimento, a opção vale um prêmio além de $(S-X)$. Um titular que deseje ter rentabilidade antes do vencimento deve vender a opção para alguém e receber $(S-X)$ mais um prêmio pelo valor do prazo.

\section{Avaliando uma opção de compra}

Uma opção de compra é um título com direito contingencial, que depende do valor e do risco de um título básico sobre o qual é subscrito. Tudo o que precisamos saber são os termos do contrato da opção de compra e o processo estocástico que descreve o comportamento do preço do ativo ao longo do tempo.

Conforme foi visto anteriormente, o valor de uma opção de compra depende fundamentalmente de cinco variáveis: o valor do ativo-objeto $S$, o preço de exercício $X, 0$ prazo de maturidade $T$, a variância do ativo-objeto, e a taxa livre-de-risco $r$, dos quais somente a variância necessita ser estimada. Temos então

$C=f\left(S, X, T, \sigma^{2}, r\right)$

A variância implícita ou instantânea pode ser calculada simplesmente usando o valor atual de uma opção de compra e os quatro parâmetros restantes conhecidos $(S, X, T$ e $r$ ) na equaçăo (01). Assim, podemos considerar em equilibrio os preços da ação e da opção de maior liquidez da série e a partir do modelo obter uma estimativa da volatilidade da ação onde

$\sigma^{2}=f(C, S, X, T, r)$

Para demonstrarmos a fórmula de BlackScholes utilizaremos os dados referentes às opções de compra da Cia. Vale do Rio Doce, constantes do Jornal do Brasil de 4 de janeiro de 1996.

O desvio padrão instantâneo ${ }^{15}$ foi calculado por estimativa, utilizando-se a equação (01) numa planilha Excel, na qual foram alimentados as demais estimativas dos parâmetros: preço da ação, $\$ 172,00$, preço de exercício, $\$ 190,00$, taxa livre-de-risco,

\section{Tabela 1}

Opções de compra da Vale do Río Doce de 04 de janeiro de 1996

\begin{tabular}{l|l|c|c|c|}
\hline Série & $\begin{array}{l}\text { Preço } \\
\text { de exercíclo }\end{array}$ & $\begin{array}{l}\text { Preço } \\
\text { de fechamento }\end{array}$ & Negócios & $\begin{array}{l}\text { Preço calculado } \\
\text { Black-Scholes }\end{array}$ \\
\hline CBB & 110,00 & 59,75 & 4.050 & 64,10 \\
\hline CBF & 130,00 & 45,00 & 1.000 & 44,60 \\
\hline CBG & 150,00 & 26,50 & 6.240 & 26,29 \\
\hline CBH & 170,00 & 11,50 & 17.640 & 12,18 \\
\hline CBI & 190,00 & 4,30 & 30.650 & 4,30 \\
\hline CBQ & 180,00 & 7,00 & 1.150 & 7,49 \\
\hline CDC & 200,00 & 2,06 & 6.000 & 2,31 \\
\hline CDL & 205,00 & 1,00 & 6.000 & 1,65 \\
\hline Ação Fechamento $=$ & $\$ 172,00$ & $r$ & $=$ & $15,33 \%$ a.a. \\
TR / 31.12 & $=4,33 \%$ a.a. & $\sigma$ & $=$ & $38,92 \%$ a.a. ${ }^{15}$ \\
Dias Maturidade $=$ & $46 / 365$ anos & &
\end{tabular}


$15,33 \%$, prazo para maturidade, $46 / 365$ e o preço da opção, \$4,30. Naturalmente, existem outras formas de estimarmos a volatilidade dos ativos.O processo adotado deveu-se à sua simplicidade e praticidade, que o tornam um método usual para as práticas de mercado.

A partir de agora estamos aptos a substituir nossas estimativas dos cinco parâmetros da equação (01) para estimar o valor de qualquer uma das demais sete opções disponíveis da Cia. Vale do Rio Doce. Por exemplo, o valor da opção CBG, cujas estimativas dos demais parâmetros são:

$$
\begin{array}{ll}
S=\$ 172,00 & X=\$ 150,00 \\
T=46 / 365 & r=15,33 \% \\
\sigma=38,92 \% &
\end{array}
$$

Inicialmente calculamos $N\left(d_{1}\right)$ e $N\left(d_{2}\right)$, pois representam as probabilidades da normal padronizada e acumuladas:

$$
\begin{aligned}
& d_{1}=\frac{\ln (s / x)+\left(r+0,5 \sigma^{2}\right) T}{\sigma \sqrt{T}} \\
& d_{1}=\frac{\ln (172 / 150)+\left[0,1533+\left(r+0,5-0,3892^{2}\right)\right](46 / 365)}{0,3892 \sqrt{46 / 365}}
\end{aligned}
$$

Consultando a Tabela da Normal Padronizada para 1,1994 temos a probabilidade acumulada:

$$
\Rightarrow N\left(d_{1}\right)=0,50+0,3848=0,8848
$$

A seguir calculamos $d_{2}$ :

$$
\begin{aligned}
& d_{2}=d_{1}-\sigma \sqrt{\mathrm{T}} \\
& d_{2}=1,1994-0,3892 \sqrt{46 / 365}=1,0613
\end{aligned}
$$

Da Tabela da Normal Padronizada para 1,0613:

$\Rightarrow N\left(d_{2}\right)=0,50+0,3557=0,8557$

Substituindo os parâmetros na equação (01) temos:

$$
\begin{aligned}
& C=S N\left(d_{1}\right)-X e^{-r T} N\left(d_{2}\right) \\
& C=\$ 172,00(0,8848)-\$ 150,00 e^{-0,1533(46 / 365)}(0,8557) \\
& C=\$ 152,19-\$ 125,90=\$ 26,29
\end{aligned}
$$

$R A E \cdot$ v. $37 \cdot$ n. $3 \cdot$ Jul./Set. 1997
O valor estimado foi de $\$ 26,29$, enquanto o valor de mercado era de $\$ 26,50$. Se repetirmos o procedimento para as demais opções constantes da Tabela 1 verificaremos que as opções com preço de exercício \$ $110,00,170,00,180,00$ e 200,00 estão subavaliadas pelo mercado, enquanto as demais estão superavaliadas. Podemos constatar ainda que, à exceção das opções com preço de exercício de $\$ 200,00$ e 205,00 (as de preço mais elevado), as demais não atingem $8 \%$ de variação em relação ao preço estimado pelo modelo Black-Scholes, o que parece indicar que a variância instantânea calculada possui uma razoável acurácia.

\section{Comentários sobre o Modelo de Precificação de Opções}

Weston e Copeland ${ }^{16}$ destacam alguns pontos importantes que são esclarecidos pelo Modelo de Precificação de Opções :

1. O preço da opção não depende do conhecimento da probabilidade de um movimento de subida do preço da ação. Informações sobre as expectativas de mercado com relação aos futuros movimentos de preços já foram capturados pelo preço atual da ação $S$. Conseqüentemente, mesmo que os investidores tenham expectativas heterogêneas sobre os preços futuros das ações, eles ainda concordarão com o valor da opção de compra relativo a seus parâmetros atuais.

2. As atitudes individuais em relação ao risco são irrelevantes na derivação da fórmula de precificação da opção de compra. A única necessidade é que as pessoas prefiram mais a menos riqueza; dessa forma, os lucros extraordinários decorrentes de arbitragens são eliminados.

3. A única variável randômica da qual depende o valor da opção de compra é o preço da ação. O preço da opção de compra não depende, por exemplo, do portfólio de mercado de todos os ativos.

Estas observações servem para enfatizar que o OPM é baseado em muito menos pressupostos que os modelos de equilíbrio, como o CAPM. Uma opção é apenas um direito contingencial sobre um ativo com risco. Uma vez observado o valor de equilíbrio do ativo, sabemos que o valor da opção deve mover-se de acordo com ele.

É importante salientar o comentário de Ross et alii ${ }^{17}$ sobre o modelo de Black-
16. WESTON, J. F. \& COPELAND, T. E., Op. cit., p. 450.

17. COX, J. C., ROSS STEPHEN A. \& RUBSTEIN, M. Option pricing: a simplified approach. Joumal of Financial Economics 7 (September), p. 229-63, 1979. 
Scholes, uma vez que os próprios Ross, Cox e Rubinstein, em 1979, desenvolveram um modelo binomial de avaliação de opções apresentado como um approach simplificado para avaliação de opções. "Não é exagero afirmar que a fórmula Black-Scholes é uma das mais importantes contribuições na área das finanças. Permite, a qualquer pessoa, calcular o valor de uma opção dados apenas poucos parâmetros. A atratividade da fórmula reside no fato de que quatro dos parâmetros são observáveis: o preço corrente da ação $S$, o preço de exercício $X$, a taxa de juros $r$, e o prazo para vencimento da opção $T$. Somente um dos parâmetros precisa ser estimado: a variância da taxa de retorno do ativo $s^{2}$."

\section{QUANTIFICANDO E PRECIFICANDO O RISCO DE CRÉDITO}

\section{Sobre o risco das empresas}

Ao falarmos neste assunto, vale lembrar que a medida tradicional de risco de uma empresa é a variância dos retornos de seus ativos. Essa mesma medida de risco, quando avaliada pelo CAPM, relaciona os retornos do ativo aos da Carteira de Mercado, sendo essa correlação conhecida como o Beta dos Ativos.

Ao efetuarmos este tipo de análise devemos ter em mente a disposição dos elementos básicos de um balanço que expressam a relação de risco existente entre seus componentes:

\begin{tabular}{|l|l|}
\hline Valor do Ativo & $\begin{array}{l}\text { Valor do Passivo } \\
\text { Valor dos Capitais } \\
\text { Próprios }\end{array}$ \\
\hline Valor do Ativo & Valor da Empresa \\
\hline
\end{tabular}

O valor da empresa será representado pela soma dos valores do passivo (capital de terceiros) e dos capitais próprios e é igual ao valor do ativo. As possíveis variações de seus componentes poderão não alterar o valor da empresa. A situação de risco total é representada pelo beta de seu ativo; no entanto, este risco é compartilhado por credores e proprietários da empresa segundo a seguinte relação:

19. MODIGLIANI, F. \& MILLER, M. H. Th cost of capital, corporation finance and the theory of investment. American Economic Review 48 (June), p. 261-97, 1958.

20. SHAPIRO, A. C. Op. cit., p. 575. sendo $W$ a proporção de capital de terceiros investido na empresa.

Brealey e Myers ${ }^{18}$ caracterizam o beta do ativo como o risco econômico ou o risco da empresa. A diferença entre os betas do ativo e de capitais próprios reflete o risco financeiro da empresa.

Modigliani e Miller ${ }^{19}$ discutiram exaustivamente os problemas decorrentes das alterações da estrutura de capital concluindo que, na ausência de impostos e outras imperfeições de mercado, o valor da firma não é afetado pelas alterações em sua estrutura financeira. Este depende basicamente de sua rentabilidade e risco e é irrelevante o arranjo do lado direito do balanço.

Nesta breve análise fica bem caracterizado que as empresas podem alterar sua relação de capitais próprios e de terceiros sem que isto implique alteração do valor da empresa. Este é um fato relevante pois, como veremos a seguir, as empresas podem usar este fundamento em benefício próprio transferindo riqueza dos credores para si mesmas sem alterar o beta do ativo, ou seja, o seu valor econômico.

Lembramos que este é um jogo de média zero. A riqueza ganha pelos proprietários da empresa corresponde ao valor perdido pelos credores. Este é o risco para o qual credores e investidores devem estar atentos.

\section{Três caminhos para aumentar o risco de falência}

Segundo Shapiro ${ }^{20}$ há três caminhos pelos quais os acionistas podem aumentar seu risco de falência e, dessa forma, tomarem a decisão de transferir riqueza dos credores para si próprios.

1. Pagando elevados dividendos. Ao pagar elevados dividendos a empresa estará reduzindo, tanto o crescimento quanto o valor de seu patrimônio líquido e consequientemente o valor dos ativos que respondem pelos direitos dos credores. No entanto, o valor da firma estará sendo reduzido por uma parcela menor que o valor dos dividendos pagos, uma vez que a redução do valor da firma é dividida com os credores.

2. Assumindo mais débito. Ao assumir mais débito de mesma prioridade ou de prioridade mais elevada a empresa estará reduzindo a razão de ativos/débito ou aumen- 
tando o seu grau de alavancagem, o que implica diretamente elevação de seu risco de insolvência. Devido ao fato de os títulos ántigos serem agora mais arriscados, seus preços declinam.

\section{No mercado financeiro, a atividade}

credilicia deve seguir a regra geral

do jogo, ou seja, a de colurar uma

taxa adequada ao risco da

operaçāo. Quando isto nāo

acontece, 0 agente financeiro ou

perde negócios por cobrar taxas

excessivanente altas ou expōe-se

ao risco sem a justa recompensa.

3. Aumentando o risco do negócio. Ao aceitar projetos com maior risco a empresa estará aumentando suas probabilidades de ganho ou prejuízo. Mas,considerando que nenhum reajuste será feito nas taxas de juros contratadas, os títulos terão uma queda em sua cotação de mercado. Se o valor da firma permanecer o mesmo ou cair para um valor inferior às perdas sofridas o valor de suas ações aumentará.

\section{Aplicação: Aurora Boreal vitima seus credores}

A empresa Aurora Boreal S.A. tem um valor total de mercado de $\$ 10$ milhões. A empresa emitiu títulos zero cupom com valor de face de 5 milhões que maturam em três anos. O desvio padrão da taxa de retorno dos ativos da firma é de $20 \%$ a.a. e a taxa livre de risco atual é de $15 \%$ a.a.Qual será o valor do patrimônio líquido e dos títulos emitidos pela Aurora Boreal? Podemos responder a essas duas questões utilizando a fórmula de precificação de opções de Black-Scholes:

$E(t)=S N\left(d_{1}\right)-X e^{-r t} N\left(d_{2}\right)$

onde:

$E(t)=$ valor corrente do patrimônio líquido da Aurora considerando um período de tempo $t$ antes do pagamento do empréstimo

$S=$ valor de mercado dos ativos da Aurora Boreal, \$10 milhões

$X=$ valor de face dos empréstimos da Aurora Boreal, $\$ 5$ milhões

$r=$ taxa livre de risco (calculada continuamente), 0,15 ao ano

$T=$ prazo para a maturidade, 3 anos

$s=$ desvio padrão, por período, da taxa de retorno dos ativos da Aurora Boreal (calculado continuamente), 0,20

$N(d)=$ valor da função densidade acumulada da normal em $d$

$$
\begin{aligned}
& d_{1}=\frac{\ln (s / x)+\left(r+0,5 \sigma^{2}\right) T}{\sigma \sqrt{T}} \\
& d_{1}=\frac{\ln (10 / 5)+\left[0,15\left(0,5 \cdot 0,2^{2}\right)\right] 3}{0,2 \sqrt{3}}=3,473 \\
& d_{2}=\frac{\ln (s / x)+\left(r+0,5 \sigma^{2}\right) T}{\sigma \sqrt{T}}=d_{1}-\sigma \sqrt{T} \\
& d_{2}=3,473-0,2 \sqrt{3}=3,127 \\
& N\left(d_{1}\right)=N(3,473) \Rightarrow 0,9997 \text { e } N\left(d_{2}\right)= \\
& N(3,127) \Rightarrow 0,9991
\end{aligned}
$$

Resolvendo para $E$, Patrimônio Líquido, o valor da opção será:

$E=10.000 .000(0,9997)-5.000 .000 e^{-0.15(3)}(0,9991)$
$E=6.811 .729$

Considerando que o Patrimônio Líquido = Ativo - Débito (Cap. Terceiros) $\Rightarrow$

Valor Mercado Débito = Valor Mercado Ativos - Valor Atual Patrimônio Líquido, ou

Débito $=10.000 .000-6.811 .729=$ \$ 3.188.271

\section{Aumentando o risco do negócio}

A empresa Aurora Boreal adota uma nova estratégia de negócios de tal forma que o desvio-padrão da taxa de retorno de seus ativos aumenta de $20 \%$ para $50 \%$ a.a. Considera-se que a mudança de estratégia não altera o beta dos ativos da firma, por isso o valor dos ativos permanecem cotados em $\$ 10$ milhões. O valor de mercado do patrimônio líquido da Aurora Boreal depois 
dessa mudança de estratégia pode ser encontrado na aplicação do modelo BlackScholes:

$$
\begin{aligned}
& d_{1}=\frac{\ln (10 / 5)+\left[0,15\left(0,5 \cdot 0,5^{2}\right)\right] 3}{0,5 \sqrt{3}}=1,753 \\
& d_{2}=1,753-0,5 \sqrt{3}=0,0887 \\
& N\left(d_{1}\right)=N(1,753) \Rightarrow 0,9600 \text { e } N\left(d_{2}\right)= \\
& N(0,887) \Rightarrow 0,8122
\end{aligned}
$$

Resolvendo para $E$, Patrimônio Líquido, o valor da opção será:

$$
\begin{aligned}
& E=10.000 .000(0,9600)-5.000 .000 e^{-0.15(3)}(0,8122) \\
& E=7.010 .592
\end{aligned}
$$

Conseqüentemente, o valor de mercado do débito será:

Débito $=10.000 .000-7.010 .592=$ $\$ 2.989 .408$

Devido ao valor da firma ser constante em $\$ 10$ milhões, o novo valor de mercado do débito da Aurora Boreal é de $\$ 2.989 .408$. Os acionistas ganharam $\$ 198.863$ (3.188.271 - 2.989.408) alterando sua estratégia de negócios. Este ganho foi inteiramente às expensas dos credores.

$\mathrm{O}$ aumento do risco de insolvência pode ainda ser verificado pela redução da probabilidade de pagamento do débito, representado pela probabilidade acumulada $N$ $\left(d_{2}\right)$ e que decresceu de 0,9991 na situação original para 0,8122 quando a empresa aumentou seu risco de $(\sigma=0,20)$ para $(\sigma=$ 0,50 ). Para se protegerem os credores deveriam colocar restrições relativas às operações corporativas e decisões de investimento.

\section{Aumentando o débito}

Considerando prioritário o interesse de seus acionistas a Aurora Boreal decide aumentar seu débito através da emissão de mais \$2 milhões em títulos e usar os recursos adicionais para recomprar parte de suas ações. $O$ desvio padrão de seus ativos permanece $(s=0,50)$ e seu débito sobe para $X$ $=\$ 7$ milhões. Assumindo que os demais valores permanecem inalterados podemos encontrar o valor das ações remanescentes aplicando mais uma vez o modelo BlackScholes:

$$
\begin{aligned}
& d_{1}=\frac{\ln (10 / 7)+\left[0,15\left(0,5 \cdot 0,5^{2}\right)\right]_{3}}{0,5 \sqrt{3}}=1,364 \\
& d_{2}=1,364-0,5 \sqrt{3}=0,498 \\
& N\left(d_{1}\right)=N(1,364) \Rightarrow 0,9138 \text { e } N\left(d_{2}\right)= \\
& N(0,498) \Rightarrow 0,6909
\end{aligned}
$$

Resolvendo para $E$, Patrimônio Líquido, o valor da opção será:

$E=10.000 .000(0,9138)-7.000 .000 e^{-0,15(3)}(0,6909)$
$E=6.054 .239$

Consequientemente, o valor de mercado do débito será:

Débito $=10.000 .000-6.054 .239=$ $\$ 3.945 .761$

Vamos analisar os resultados desta última operação para verificar qual a sua influência na riqueza dos acionistas.Consideremos que a Aurora Boreal, antes desta última operação, emitiu 5.000 títulos de $\$ 1.000$ cada. O valor agregado desses títulos era de $\$ 2.989 .408$, ou $\$ 597,88$ cada um $(2.989 .408 / 5000)$. Com a última operação a empresa totalizou a emissão de 7.000 títulos, cujo valor agregado atingiu $\$ 3.945 .761$, ou $\$ 563,68$ cada título (3.945.761/7.000).

A queda no valor dos títulos individuais deveu-se ao aumento dos riscos de falência, ou seja, o aumento da alavancagem financeira da empresa que passou de 1:1 para 1:2,3. A alteração na estrutura de capital da empresa implica aumento da variabilidade dos retornos sobre o patrimônio líquido e, conseqüentemente, no aumento das chances de falência. A empresa não sofreu perdas devido à mudança de sua estrutura de capital, seu valor econômico, nem o beta de seu ativo permaneceu inalterado. Os investidores descontarão dos títulos o aumento do risco.

\section{$5.000(597,8816-563,6801)=\$ 171.007$}

Este valor será a perda imputada aos credores por causa da desvalorização de seus títulos.Para calcular o ganho dos acionistas devemos considerar que o patrimônio líqui- 
do anterior era de $\$ 7.010 .592$. Então foram emitidos mais 2.000 títulos a $\$ 563,68$, cujo resultado foi utilizado na recompra de ações - os acionistas receberam todo esse valor - ficando o patrimônio líquido reduzido para:

$7.010 .592-(2.000 \times 563,68)=\$ 5.883 .232$

Entretanto, o valor das ações remanescentes declinou para somente $\$ 6.054 .239$. Dessa forma, os acionistas tiveram um ganho adicional de \$171.007 (6.054.239 5.883.232) igual à perda sofrida pelos credores. A transferência de riqueza efetivamente ocorreu. Para protegerem-se os credores deveriam exigir que a emissão mais recente ficasse subordinada a seus direitos anteriores.

\section{Pagando dividendo extra para os acionistas}

Tentando maximizar ainda mais a riqueza de seus acionistas, a Aurora Boreal finalmente resolve recompensá-los com um pagamento extra de dividendos no valor de \$2 milhões em dinheiro; para tanto, vende $20 \%$ de seus ativos e distribui o resultado da operação entre seus acionistas. Após a distribuição, os ativos da empresa são reduzidos para $\$ 8$ milhões.

Com o débito já estabilizado em $\$ 7 \mathrm{mi}-$ lhões e o desvio padrão de $50 \%$ sobre a taxa de retorno de seus ativos remanescentes, o valor de seu patrimônio líquido pode ser novamente encontrado pela aplicação da fórmula de Black-Scholes:

$$
\begin{aligned}
& d_{1}=\frac{\ln (8 / 7)+\left[0,15\left(0,5 \cdot 0,5^{2}\right)\right] 3}{0,5 \sqrt{3}}=1,107 \\
& d_{2}=1,753-0,5 \sqrt{3}=0,887 \\
& N\left(d_{1}\right)=N(1,107) \Rightarrow 0,8658 \text { e } N\left(d_{2}\right)= \\
& N(0,241) \Rightarrow 0,5951
\end{aligned}
$$

Resolvendo para $E$, Patrimônio Líquido, o valor da opção será:

$$
\begin{aligned}
& E=8.000 .000(0,8658)-7.000 .000 \theta^{-0,15(3)}(0,5951) \\
& E=4.270 .232
\end{aligned}
$$

Conseqüentemente, o valor de mercado do débito será:

$$
\text { Débito }=8000.000-4.270 .232=
$$
$\$$ 3.729.768

Apesar de os acionistas terem recebido dividendos de $\$ 2$ milhões, o valor de mercado das ações declinou somente 1.784.007 (6.054.239 - 4.270.232). Isto significa que os acionistas ganharam mais $\$ 215.993$ (2.000.000 - 1.784.007) decorrentes da redução dos ativos destinados a garantir os direitos dos credores, aumentando o valor de sua opção de falência. $O$ ganho dos acionistas iguala a perda do valor de mercado dos títulos dos credores de $\$ 215.993$ (3.945.761 - 3.729.768). Para se protegerem os credores deveriam restringir dividendos $\mathrm{e}$ outras ações que possam implicar redução de colateral ou garantias complementares.

\section{Precificando o risco de crédito}

Vimos até aqui como a Aurora Boreal, sem alterar o valor da firma, vitimou seus credores aumentando apenas seu risco idiossincrático ou não sistemático. A reação dos credores, no entanto, poderia ter ocorrido de forma passiva, através da inclusão de cláusulas contingenciais que os protegesse de ações contrárias aos seus interesses.

A variabilidade do valor de mercado do crédito das empresas ocorre tanto voluntariamente quanto como uma reação às medidas econômicas, pois alteram o ambiente operacional em que atuam. Independentemente da motivação que levou as empresas a terem o valor de mercado de seu crédito alterado, os credores, principalmente os bancos, que fazem dessa a sua atividade fim, devem precificar corretamente essa variação de risco.

Utilizando o OPM conseguimos levantar o valor atual do crédito da empresa para diferentes situações de risco. Precificar este risco torna-se a tarefa de recompor o valor original do crédito, através de uma taxa de juros adequada. Weston e Copeland ${ }^{21}$ suprem a fórmula para resolver este problema com a simplicidade desejada:

$$
B=D e^{-K_{b} T} \Rightarrow K_{b}=\ln (B / D) T^{-1}
$$

sendo

$B=$ débito sujeito à risco (valor de mercado do crédito)
21. WESTON, J.F. \& COPELAND, T. E., Op. cit., p. 460. 
$D=$ valor de face do débito

$e=$ base do sistema de logaritmos naturais

$T=$ prazo para a maturidade

$k_{b}=$ taxa unitária a ser cobrada até a maturidade

Vejamos, através de uma aplicação, como os credores podem ajustar as taxas cobradas às variações de risco das empresas.

\section{Aplicação : credores reagem às manobras da Aurora Boreal}

Vejamos agora como os credores da $\mathrm{Au}$ rora Boreal S.A. poderiam ajustar suas taxas às diversas situações de risco criadas pela empresa.

\section{Déblto original}

$$
\begin{aligned}
& B=3.188 .271 \quad D=5.000 .000 \quad T=3 \\
& 3.188 .271=5.000 .000 e^{-k b(3)} \\
& k_{b}=\ln (3.188 .271 / 5.000 .000)(-3)^{-1} \\
& k_{b}=0.15
\end{aligned}
$$

Considerando que este é o débito original da empresa, podemos esperar que esta seja a taxa ajustada ao risco inicial da operação.

\section{Aumentando o risco do negócio}

Ao aumentar o risco do negócio a firma reduziu o valor de mercado de seu crédito para \$ 2.989.408. Aplicando-se a equação (04) encontraremos o valor da taxa a ser cobrada da Aurora Boreal ajustada ao seu nível de risco atual:

$$
\begin{aligned}
& \$ 2.989 .408=\$ 5.000 .000 \mathrm{e}^{-\mathrm{kb}(3)} \\
& \mathrm{k}_{\mathrm{b}}=0.1715
\end{aligned}
$$

\section{Aumentando o débito}

Para avaliarmos o valor de mercado do crédito original basta ajustá-lo a partir da situação anterior, isto é, descontar do valor de mercado anterior o prejuízo de \$ 171.007 sofrido pelos credores iniciais. Neste caso, o valor de

$$
\begin{aligned}
& B=\$ 2.989 .408-171.007=\$ 2.818 .401, \log 0 \\
& 2.818 .401=5.000 .000 e^{-k b(3)} \\
& k_{b}=0,1911
\end{aligned}
$$

\section{Pagando dividendo extra para os acionistas}

Novamente torna-se necessário um ajuste sobre a situação anterior, descontando-se dos credores originais a parcela que lhes corresponde do lucro extraordinário dos acionistas:

$$
\begin{aligned}
& B=\$ 2.818 .401-215.993(5 / 7)=\$ 2.664 .120, \log 0 \\
& 2.664 .120=5.000 .000 e^{-k b(3)} \\
& k_{b}=0,2099
\end{aligned}
$$

A Tabela 2 nos mostra a correspondência entre o aumento de risco do crédito, re-

\section{Tabela 2}

Probabllidade de pagamento e taxa de juros ajustada ao risco da Aurora Boreal S.A.

\begin{tabular}{|l|c|c|c|c|c|}
\hline Situação & $\begin{array}{l}\text { Valor de Mercado } \\
\text { do Crédito }\end{array}$ & $\begin{array}{l}\text { Alavancagem } \\
\text { Empresa }\end{array}$ & $\begin{array}{l}\text { Risco } \\
\text { Ativo }\end{array}$ & $\begin{array}{l}\text { Probabilidade } \\
\text { Pagamento }\end{array}$ & $\begin{array}{l}\text { Taxa Ajust. } \\
\text { ao Risco }\end{array}$ \\
\hline Original & $\$ 3.188 .271$ & $1: 1$ & 0,20 & 0,9991 & $15,00 \%$ \\
\hline Aum. Risco & 2.989 .408 & $1: 1$ & 0,50 & 0,8122 & $17,15 \%$ \\
\hline Aum. Déblto & 2.818 .401 & $1: 2,3$ & 0,50 & 0,6909 & $19,11 \%$ \\
\hline $\begin{array}{l}\text { Pgto. } \\
\text { Dividendo. }\end{array}$ & 2.664 .120 & $1: 7$ & 0,50 & 0,5951 & $20,99 \%$ \\
\hline
\end{tabular}


presentado por seu valor declinante de mercado - à medida que a empresa aumenta seu risco ou seu grau de alavancagem - e a redução da probabilidade de pagamento do título, com o consequiente aumento das taxas de juros para manter equilibrada a relação risco/ retorno do credor.

\section{Um dos aspectas surpreendentes}

ao utilizarmos o DPM para avaliar o patrimônio liquido de uma empresa

alavancada, è a constataçāo que os decisores da empresa podem deliberadamente transferir riqueza dos credores para os proprietários sem alterar o valor da lirma, uma vez que o lucro de um agjente será equilibrado pelo prejuízo do outro.

\section{CONCLUSÃo}

Face à nova realidade econômica brasileira, passamos a conviver com inflação controlada e taxas de juros relativamente baixas com tendência à queda. Em virtude disto, os bancos estão voltando-se para sua atividade de intermediários financeiros.

No mercado financeiro, a atividade creditícia deve seguir a regra geral do jogo, ou seja, cobrar uma taxa adequada ao risco da operação. Quando isto não acontece, o agente financeiro perde negócios por cobrar taxas excessivamente altas ou expõe-se ao risco sem a justa recompensa.

Ao longo do texto foi apresentado o Modelo de Precifícação de Opções de BlackScholes (Option Pricing Model) como uma alternativa válida para a quantificação e precificação de risco de crédito. Este modelo apresenta hipóteses bem menos restritivas que o Modelo de Precificação de Ativos de Sharpe (Capital Asset Pricing Model), podendo ser relaxadas sem grandes prejujzos. Estas características tornam o OPM um modelo prático e eficiente quanto às suas condições de uso.

Ainda com relação à possível compara- ção entre os modelos citados vale lembrar o estudo de $\mathrm{Hsia}^{22}$ desenvolvido em 1978 e 1981 e que combina o OPM, o CAPM e o teorema de Modigliani-Miller provando a consistência entre os dois modelos e a teoria subjacente.

Um dos aspectos surpreendentes, ao utilizarmos o OPM para avaliar o patrimônio líquido de uma empresa alavancada, é a constatação que os decisores da empresa podem deliberadamente transferir riqueza dos credores para os proprietários, sem alterar o valor da firma, uma vez que o lucro de um agente será equilibrado pelo prejuízo do outro. Este torna-se um assunto relevante pois, com a dinâmica das atividades econômicas e sua operacionalização, as relações de risco entre credores e proprietários da empresa estão sendo continuamente alteradas de forma voluntária ou não. Apesar dos credores poderem proteger-se com cláusulas contingenciais nos contratos, essa dinâmica torna bastante difícil o acompanhamento de seu fiel cumprimento.

O Modelo de Precificação de Opçōes, além de avaliar o patrimônio líquido da empresa, fornece o valor de mercado do seu crédito; desta forma, o OPM permite quantificar o risco atualizado que o credor está correndo. Uma vez conhecido o valor de mercado do créditn, a tarefa de precificar o risco atualizado torna-se fácil; basta calcular a taxa que iguale este ao valor de face do débito original.

Complementarmente, o OPM fornece uma medida alternativa de risco, ou seja, a probabilidade acumulada do débito a ser pago, o valor de $\mathrm{N}\left(\mathrm{d}_{2}\right)$.

Conclui-se que através do Modelo de Precificação de Opções se pode efetivamente avaliar o risco de crédito de cada cliente considerando o risco do retorno de seus ativos, seu grau de alavancagem e o prazo da operação, ou seja, as variáveis de seu risco idiossincrático ou não-sistemático. O risco de mercado será levado em conta no modelo através da taxa de juros vigente.

Finalmente, ao igualarmos o valor de mercado do crédito a seu valor de face original por intermédio de uma taxa de juros adequada estamos precificando os contratos segundo seu nível de risco, objetivo último das empresas fornecedoras de crédito.
22. HSIA, C. C. Coherence of the modern theories of finance. Financial Review (Winter) p. 27-42, 1978 